\title{
OPTIMIZATION OF SMELTING PROCESS BY SURFACE RESPONSE MODELING FOR PIG IRON PRODUCTION
}

\author{
Gopal Ghosh Roy ${ }^{1}$, Chanchal Biswas ${ }^{2}$, Arnab Swarnakar ${ }^{3}$, Rajib Dey ${ }^{4}$, Manoj Kumar Mitra ${ }^{5}$ \\ ${ }^{1}$ Vizag Steel Plant, Andhra Pradesh, Visakhapatnam - 530031, India \\ ${ }^{2}$ Department Metallurgical and Material Engineering, Jadavpur University, Kolkata-700032, India \\ ${ }^{3}$ Ll Ansari Trading Enterers LLC, Ruwi, 112, icebox No. 1832, Sultanate of Oman, \\ ${ }^{4}$ Department Metallurgical and Material Engineering, Jadavpur University, Kolkata-700032, India \\ ${ }^{5}$ Department Metallurgical and Material Engineering, Jadavpur University, Kolkata-700032, India
}

\begin{abstract}
The pre reduced iron-carbon composite products have found usages in electric smelting process as well as in BF/BOF industry for producing pig iron. The aim of this study is to utilize the iron ore fines of different fraction; boiler grade coal and plant waste coke dust for reduction and assess the feasibility of smelting in closed Raising Hearth Furnace for lab scale pig iron production. The statistical model of Box Behnken Design (BBD) method is successfully utilized to optimize the process parameter for smelting experiments. The reduced nuggets are charged in the standard raising hearth furnace for smelting at three different temperatures, time and lime percentage. The raw materials and reduced specimens are characterized using X-ray Diffractometers (XRD) Scanning Electron Microscope, (SEM) Energy Dispersive X-ray spectrometer (EDX), and Chemical Analysis method. The smelted samples are characterized by using XRD, SEM-EDX, and OES analysis. The microstructure analysis is carried out by an optical microscope for the metallic part of the samples after smelting. It is observed that better slag metal separation is achieved when higher smelting temperature, time and higher percentage of calcined lime are used.
\end{abstract}

Keywords: Nugget Making, Solid State Reduction, Direct Reduced Iron, Box Behnken Design (BBD), Smelting

\section{INTRODUCTION}

The iron ore is one of the most important raw materials for production of steel. The estimated world reserves of iron ore is around 87,350 MT. [1] The majority part of iron ore reserves are in the form of iron ore fines. At present usages of iron ore fines are limited \& used in sintering \& pelletization process to make it suitable for usages at blast furnace. However, there is limitation in the sizes of iron ore fines for usages at sintering \& pelletization process. So there is a need to find out alternate means so as to maximise the usages of iron ore fines in iron and steel making.

The role of good quality coke is also very important in the process of iron making through BF route. To produce good quality coke low ash prime coking coal are generally used. As per estimation the overall global coal reserves are around 861 Billion Tonnes. Out of the total reserves only few countries like Australia, USA, Russia, Canada, China and New Zealand have substantial quantities of low ash coking coal suitable for coke making [2]. The coal reserves in USA $\&$ New Zealand have more sulphur which restricts their usages in the coal blend. The coke making process is also extremely hazardous with many environmental related issues. However there is abundant availability of high ash non-coking coals (boiler grade coal) at different parts of the world.

In India itself out of 285 Billion Tonnes of coal reserve, approximately 250 Billion Tonnes of coal is of high ash non-coking coal [3]. So, a need is felt for finding out an alternate method for usages of iron ore fines along with high ash non coking coal \& to convert them into a value added product which could be used further for iron making.

The present work involves optimization of melting process of pre reduced nugget with variable of time, temp \& $\%$ of Lime with the help of Box-Behnken Design (BBD). The nuggets are made from intermixing of Iron ore fines of different Sizes along with combination of carbonaceous materials like high ash boiler coal, coke dust compacted under high pressure. Several studies on smelting reduction/ melting of iron ore, metal-slag phase separation etc on iron ore-carbon composites have been reported in the literature. Many works have been done on optimization of process parameter using Box-Behnken Design (BBD).

P. Bukovec et al studied the effect of process condition \& binder content on yield \& pellet characteristic during process of pellet making by melt pelletization in a shear mixer. Two different composition were used to produce pellet by melt pelletization. The variables under investigation were considered as impeller speed, mixing time, mixer load, and binder concentration. Total twenty seven experiments were conducted based on Box-Behnken experimental design. Rheological properties of Binder reported to have the controlling effect on the process as well as on the quality of the pellet. [4] Kulchaya Tamong et al worked on the development of a hydrological process to recover the harmful metal like Zinc, Manganese, Nickel, Cadmium and Cobalt from spent batteries before they were 
disposed off. The influence of various parameters like acid concentration, solid/liquid ratio, retention time and number of leaching steps were studied by the usages of Boxbehnken Design (BBD) on the removal of harmful metal from spent batteries. It was reported that solid/liquid ratio and acid concentration seems to be having paramount influence on solubilisation of the harmful metals in spent batteries. The various optimum conditions for highest leaching of metal from spent batteries were also reported. [5]

M. Eisapour et al studied the process optimization of uranium bioleaching in a stirred tank reaction using a bacteria culture by Box-Behnken Design (BBD). The three variables were considered as pulp density, agitation speed and aeration rate. The model predicted a value of $99.99 \%$ of uranium extraction with specific values of the above three variables. The percentage of error was reported as $4.99 \%$ as compared to measured data. [6] A study was done on the process optimization of leaching of $\mathrm{Zn}$ from dust generated from Electric arc furnace during making of steel. The BoxBehnken design model was used for the above study. The variables were considered as concentration of sulphuric acid, leaching temperature, leaching time and liquid/solid ratio. It was reported that the predicted values were found to be very similar to the observed values. The most influencitial factor on leaching of Zinc was reported as concentration of $\mathrm{Zn}$ and leaching time. [7] N. Aslan et al worked on the optimization of Lead floatation by BoxBehnken design (BBD). The three variables considered were Potassium Amyl Xamthate (KAX), sodium sulfide $\left(\mathrm{Na}_{2} \mathrm{~s}\right)$ and $\mathrm{PH}$ value. The optimum condition of the above three variables for highest recovery of Lead were reported in the paper. The model predicted a recovery of $84.58 \%$ of lead in optimum condition and the predicted values were reported to be in line with experimental result. [8]

DING Yin-Gui et al evaluated on the isothermal reduction of carbon bearing pellets made of boron containing iron concentrate \& pulverized coal, from 1623 to $1723 \mathrm{~K}$ with different heating time. It was concluded that the heating temperature \& time played a very crucial role in the metallization of the iron carbon composite pellet. It was also concluded that reduced iron \& boron rich slag was separated at $1673 \mathrm{~K}$ for $15 \mathrm{~min}$ of process time. It was also reported that the recovery of iron \& boron were $98 \%$ and $97 \%$ respectively [9]. Studies were done by Alberto Eloy, Anduze Nogueira et al on the effect of slag composition on the high temperature reduction of Iron ore carbon composite. The slag composition was varied by addition of Portland cement, Silica \& Alumina to adjust the expected Liquidus temperature of slag. It was concluded that Iron carburization was favored with Low Liquidus temp of slag. [10] Takashi Matsui et al worked on the influence of gangue composition on the melting behavior of carbon reduced iron ore. It was reported that melting \& carburization starts at a lower temp when Iron and carbon reacts without gangue layer whereas, the presence of gangue layer forbids the direct contact of Iron and carbon till the gangue layer starts melting. It was also reported that addition of flux helps in lowering the melting point of gangue material there by lowering the melting \& carburization temp. [11] A study was done to observe the effect of slag foaming on the reduction of iron oxide in molten slag. It was concluded that Slag foaming changes the reaction rate and the mass transfer in the slag phase predominantly controls the rate of reduction [12].

Guo Zhancheng et al evaluated on the thermodynamics and kinetics of sulphur during coal gasification phase in a liquid iron bath in coal based iron smelting reduction process. It was concluded that, for obtaining low sulphur iron and gas, high basicity of slag was required. It was also concluded that high pressure, temperature, \& carbon content in liquid iron and high hydrogen content in coal were not favorable to obtain low sulphur gas. [13] M. Benvenuti studied the effect of $\mathrm{Sn} / \mathrm{W}$ on metal \& slag in $\mathrm{Sn} / \mathrm{W}$-rich hematite ore. It was verified that depending upon operating condition, tin can significantly partition at the rate of $50 \%$ of original content of ore into the metallic iron phase whereas tungsten was predominantly transferred into the silicate slag. [14] Hiroyuki Katayamtae et al studied the effect of thick slag layer in the smelting reduction of iron ore and its characteristics. The study reported the relationship among various operational conditions and discussed the performance of operation along with slag characteristic. [15] A study was done to observe the microstructure of prepared solid metallic iron at laboratory scale \& the same was compared to the pig iron obtained from blast furnace. It was concluded that the reduced iron composite as per experimental condition was having higher apparent density $(6.7-7 \mathrm{~g} / \mathrm{cm} 3) ; \&$ higher iron content (95-97\%) and possess similar microstructure as that of the pig iron from blast furnace with.[16]

Guang Wang et al worked on a complex ore containing Iron, Boron \& Magnesium of Ludwigite source of China. The experiment was conducted on pellets made from ore from Ludwigite source of China and pulverized coal. The pellets were reduced in a reducing atmosphere under isothermal condition at a high temperature. The effect of reduction temperature and $\mathrm{C} / \mathrm{O}$ (mole ratio) on the degree of metallization along with melting morphology of the samples was studied. It was reported that reduction \& melting rate of pellet increases with increasing rate of $\mathrm{C} / \mathrm{O}$ ratio. It was also reported that at $1673 \mathrm{~K} \&$ for $12 \mathrm{~min}$ of reaction time, the iron \& slag separates very well. [17] N. Narcin et al worked on the reduction of iron ore pellets with lignite coal in a rotary tube furnace. Coal consumption ratios, temperature of environment \& residence time of reaction were considered as the variables. It was concluded that the most effective temperature for reduction was $1000^{\circ} \mathrm{C}$ with coal consumption ratio of $0.40 \%$ and the reduction time of 90 min. The metallization of pellet was reported as 93\%. [18]

\section{MATERIALS AND METHOD}

\subsection{Material Used}

Iron ore fines, Coke dust and Boiler grade coal are collected from Visakhapatnam steel plant, Vizag, Andhra Pradesh, India. Bentonite is procured from JSW Steel, Toranagallu, 
Bellary, Karnataka, India. Lime and molasses are obtained from Tata steel plant, Jamshedpur, Jharkhand, India.

\subsection{Nuggets Making}

Iron ore is crushed by jaw crusher and roll crusher. It is then subjected to sieve analysis to get different size of particles. Three ranges of size fractions are selected for nuggets, coarse $-0.211+0.152 \mathrm{~mm}$ or $(-72,+100)$, semi coarse 0.152 to $+0.104 \mathrm{~mm}$ or $(-100,+150)$ and fines -0.104 to $+0.066 \mathrm{~mm}(-150,+240)$ BSS standard mesh size. $4 \%$ Bentonite, $4 \%$ Molasses and $4 \%$ Water are mixed with different proportions of namely coarse, semi-coarse and fine along (50:25:25) with coke dust and boiler grade coal to produce the nuggets. Then they are mixed thoroughly to get a homogenous mixture as far as possible and cured overnight before making nuggets. 12.5 gram of that mixture is taken into cylindrical die. The die along with mixture is placed in the hydraulic press (hand operating). The pressure applied to the die is $350 \mathrm{Kg}$. The die is kept in rest for a while (1 minute). Cylindrical shaped samples are taken out of the die. The nuggets are studied to assess their mechanical properties results such as shatter index and abrasion index.

\subsection{Reduction of Nuggets}

Nuggets are reduced in a PID controlled laboratory scale horizontal tube furnace at $1200^{\circ} \mathrm{C}$ for 60 minute in closed atmosphere.

\subsection{Smelting of Reduced Nuggets}

Graphite crucible is used for smelting purpose. This crucible is preheated before smelting. Thereafter, the crucible is put inside raising hearth furnace for heating at smelting temperature. The smelting is carried out of the reduced sample in three different temperatures (1450, 1500 and $\left.1550^{\circ} \mathrm{C}\right)$, time $(30,45$ and 60 minutes) and lime percentage $(4,8$ and 10$)$ respectively. When the temperature is reached, reduced nuggets are placed into the crucible and kept for fixed duration in that particular temperature. After that, the crucible is taken out and cooled. After that metal part and slag part are separated and then they are characterized.

\subsection{Box Behnken Design (BBD)}

Box Behnken Design (BBD) is used to optimize the three process parameters of smelting- smelting time, temperature and lime percentage. The model is analyzed on the basis of pure metal recovery with slag interrupt of the smelting process.

\subsection{Characterizations}

\subsubsection{Characterization of Raw Materials and}

\section{Reduced Nuggets}

The raw materials, reduced nuggets are characterised by Xray diffraction analysis using X-ray diffraction in Rigaku Ultima-III machine, using $\mathrm{Cu} \mathrm{K} \alpha$ radiation in the range of $2 \theta$ from $20^{\circ}$ to $80^{\circ}$ with a scan speed of $5^{\circ} / \mathrm{min}$ ), WDXRF (MagiX2424, PANatytical Super Q), SEM (model no- JEOL JSM-8360) and EDX (oxford instrument). Proximate analysis of boiler grade coal is also carried out and the results are compared with the TGA/DTA results. Boiler grade coal and coke dust fines are characterized by TGA/DTA (Perkin-Elmer instrument, model- Pyris diamond TG-DTA) in the range of $37^{\circ} \mathrm{C}$ to $900^{\circ} \mathrm{C}$ at the rate of $10^{\circ} \mathrm{C} / \mathrm{min}$ in Nitrogen atmosphere. Shatter and abrasion index of the nuggets are obtained in the standard shatter and abrasion lab scale apparatus. The chemical analysis of the reduced samples is performed by the standard procedure of the Bureau of Indian Standards (BIS 10812:1992).

\subsubsection{Characterizations of Smelted Nuggets}

Smelting samples are characterized by XRD, SEM, EDX, OES and Microstructure analysis. The microstructure analysis is carried out by an optical microscope model noCarl Zesis AXIO Imager A1m. Characterizations of smelted samples are done by OES analysis using Optical emission spectrometer (Shimadzu GVM-1014S made in China).

\section{RESULTS AND DISCUSSION}

\subsection{WDXRF Analysis of Iron Ore}

Elemental analysis of ore fines, total Fe content of the ore and major oxide concentrations are measured by WDXRF is given in Table 1 shows the details of the analysis in percentage $(\%)$.

Table 1: WDXRF result of iron ore

\begin{tabular}{|l|l|l|l|l|l|l|l|l|l|l|}
\hline $\mathbf{F e}(\mathbf{T})$ & $\mathbf{S i O}_{\mathbf{2}}$ & $\mathbf{A l}_{\mathbf{2}} \mathbf{O}_{\mathbf{3}}$ & $\mathbf{M n O}$ & $\mathbf{M g O}$ & $\mathbf{C a O}$ & $\mathbf{N a}_{\mathbf{2}} \mathbf{O}$ & $\mathbf{K}_{\mathbf{2}} \mathbf{O}$ & $\mathbf{T i O}_{2}$ & $\mathbf{S}$ & $\mathbf{P}_{\mathbf{2}} \mathbf{O}_{\mathbf{5}}$ \\
\hline 64.05 & 4.03 & 2.29 & 0.05 & 0.28 & 0.36 & 0.02 & $<0.01$ & 0.24 & 0.1 & 0.06 \\
\hline
\end{tabular}

\subsection{Proximate Analysis of Boiler Coal and Coke}

\section{Dust}

The amount of fixed carbon, moisture content, volatile matter and ash content for Coke dust and boiler grade coal are calculated using the result of proximate analysis and are given in Table 2.
Table 2: Proximate analysis of boiler grade coal and coke dust

\begin{tabular}{|l|l|l|l|l|}
\hline Sample & $\begin{array}{l}\text { Fixed } \\
\text { carbon }\end{array}$ & $\begin{array}{l}\text { Volatile } \\
\text { matter }\end{array}$ & Moisture & Ash \\
\hline $\begin{array}{l}\text { Coke } \\
\text { dust }\end{array}$ & $79.46(\%)$ & $4.01(\%)$ & $0.53(\%)$ & $16(\%)$ \\
\hline $\begin{array}{l}\text { Boiler } \\
\text { grade } \\
\text { coal }\end{array}$ & $28.08(\%)$ & $28.31(\%)$ & $7.4(\%)$ & $36.21(\%)$ \\
\hline
\end{tabular}




\subsection{TGA/DTA Analysis of Boiler Coal and Coke Dust}

Fig. 1 shows that TG/DTA analysis of the boiler grade coal. The green line is the TG curve and the red line is the DSC curve.

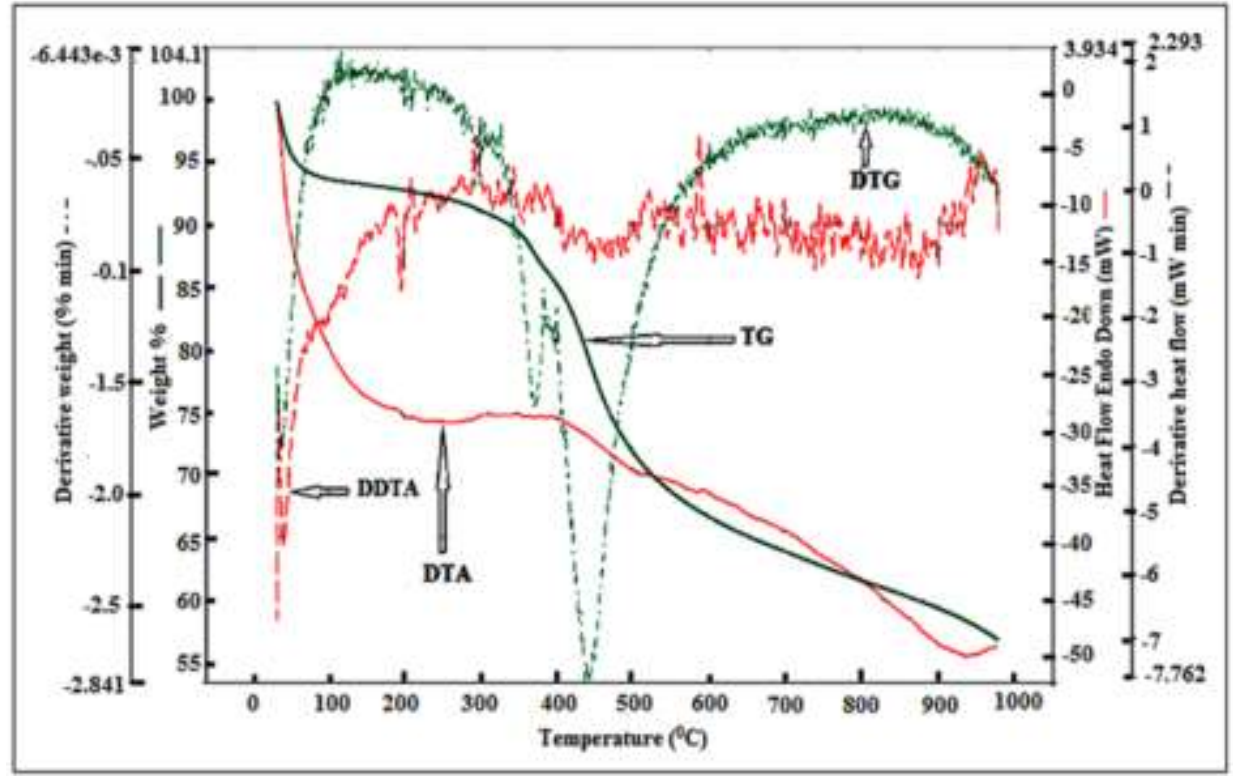

Fig. 1: TG/DTA analysis of the boiler grade coal

The nature of the weight loss conforms to the data from the proximate analysis of the boiler coal. The graph shows a weight loss up to $110^{\circ} \mathrm{C}$, which is obviously the expulsion of the moisture (7-8 \%) in the coal. The major weight loss from 400 to $550^{\circ} \mathrm{C}$ is the removal of the volatile matter (25-30
$\%)$. The following weight loss at a very slow rate may occur due to soot formation or mild oxidation by the trace amount of oxygen present in nitrogen which is used as a shielding gas in the experiment.

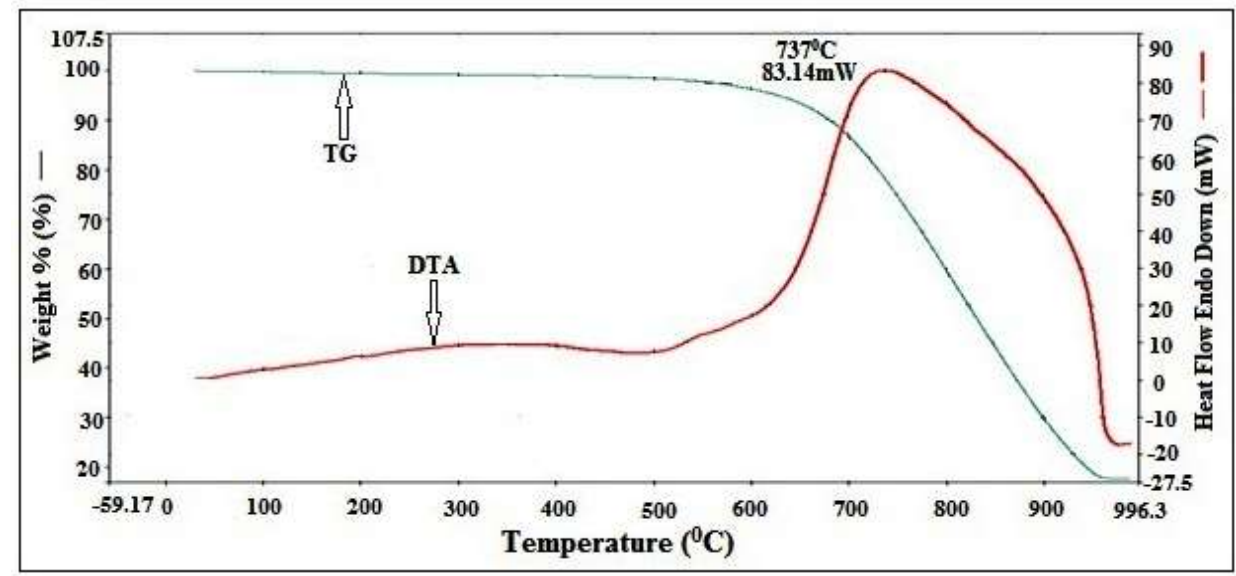

Fig. 2: TG/DTA plot of the coke dust

Fig. 2 is the TG/DTA plot of the coke dust. The graph shows a weight loss staring at $737^{\circ} \mathrm{C}$, due to burning of coke dust. The temperature ranges $(737 \text { to } 1000)^{0} \mathrm{C}$ the maximum weight loss to burning of fixed carbon of coke dust.

\subsection{Mechanical Properties of the Nuggets Samples}

Mechanical properties such as shatter and abrasion index of agglomerated iron ore nuggets are calculated before reduction of nuggets. The value of shatter and abrasion index (92.86 and 90.84) of iron ore nuggets is calculated. The result shows good mechanical stability of the nuggets.
After that nuggets are charged standard tube furnace for reduction.

\subsection{XRD Analysis of the Reduced Nuggets}

XRD analysis of reduced iron ore, coke dust and boiler grade coal nuggets are performed to identify the Phase analysis during carbothermal reduction process are evaluated by XRD. The XRD pattern of the reduced nuggets at $1200^{\circ} \mathrm{C}$ in 60 minute is given in Fig. 3. 


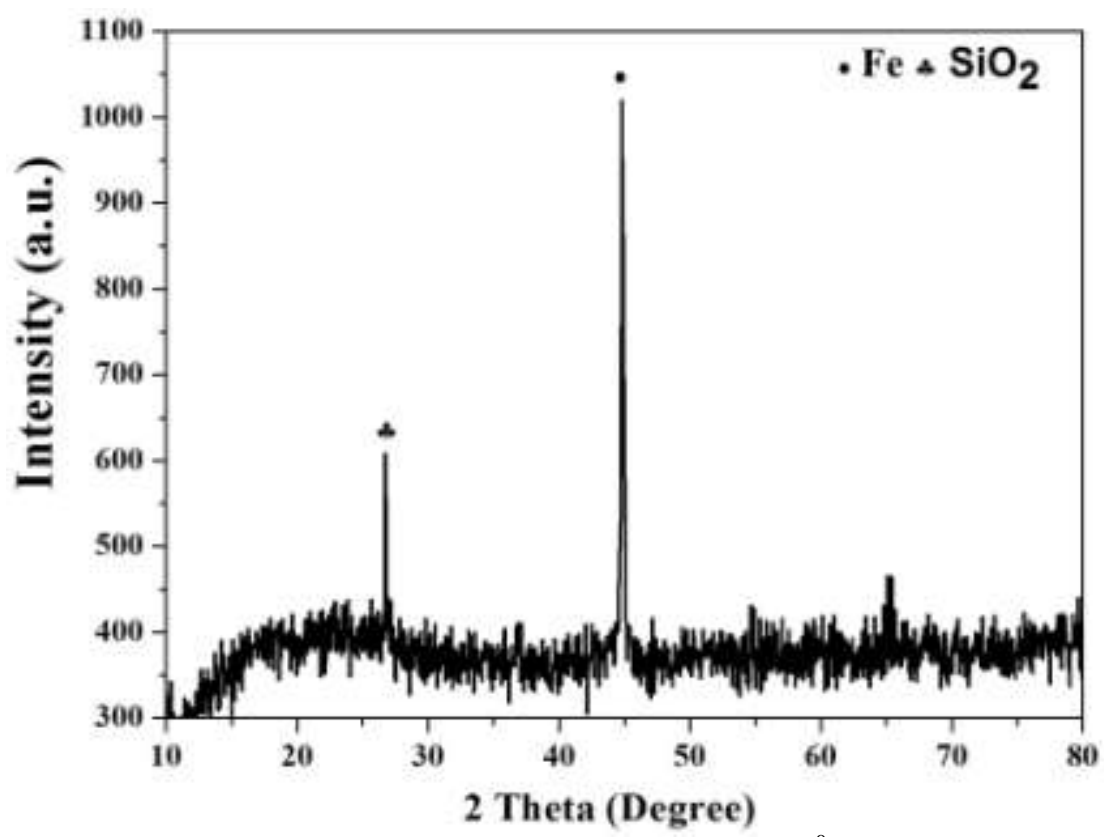

Fig. 3: $\mathrm{XRD}$ analysis of the reduced sample at $1200^{\circ} \mathrm{C}$ in 60 minute

It is observed that the major peak is of iron $(\mathrm{Fe})$ along with significant peaks of Silica ( $\mathrm{SiO} 2)$ is observed due to the presence of higher ash content of the boiler grade coal.

\subsection{Extent of Reduction and Degree of}

\section{Metallization of the Reduced Samples:}

The extent of reduction is calculated by measuring the weight loss. Losses of weights are due to removal of oxygen from iron oxides, binder (bentonite and molasses) and removal of volatile matter and fixed carbon from coal/coke dust. The details calculation is given in appendix 1 .

Chemical analysis of the reduced samples is performed by the standard procedure of the Bureau of Indian Standards (BIS 10812:1992). In brief, a $0.2 \mathrm{~g}$ sample is taken in a dry conical flask and a $100 \mathrm{ml}$ freshly prepared ferric chloride solution ( $10 \mathrm{~g}$ in $100 \mathrm{ml}$ distilled water) is added in it. Then it is stirred for $30 \mathrm{~min}$. A prepared acid mixture $(25 \mathrm{ml}$ hydrochloric acid and $25 \mathrm{ml}$ orthophosphoric acid) are added to the conical flask and cooled. After cooling, the solution is titrated against $0.1 \mathrm{~N}$ potassium dichromate solution using BDS indicator. The burette reading is then recorded and calculated to get the total metallic iron content of the reduced sample.
The extent of reduction and degree of metallization of the reduced nuggets is calculated as 87.13 and $73.24 \%$. This reduced sample is charged in Raising Hearth Furnace for pig iron production.

\subsection{Smelting of the Reduced Samples}

The reduced nuggets are charged in the standard raising hearth furnace for smelting at three different temperatures $\left(1450^{\circ}, 1500^{\circ} \mathrm{C}, 1550^{\circ} \mathrm{C}\right)$ for three different times $(30,45$ and 60) minutes with three different limes ( 4, 8 and 12) percentage. Graphite crucible is used for smelting purpose. This crucible is preheated before smelting. Thereafter, the crucible is put inside raising hearth furnace when the temperature is reached; reduced nuggets with varying lime percentage are placed into the crucible in different times for smelting. After completion of the smelting process, the crucible is taken out and cooled. After that metal part and slag part are separated and characterized.

\subsection{Optimizations of Process Parameter of Smelting}

\section{Process using Box Behnken Design}

Three different variables are: (i) Smelting Time (A) (ii) Smelting Temperature (B) (iii) Lime Percentage (C) each of which is assessed at three coded levels lower $(-1)$, middle $(0)$, higher $(+1)$ as shown in Table. 3 .

Table 3 Variables of Box Behnken Design

\begin{tabular}{|c|c|c|c|c|c|c|c|}
\hline & & & \multicolumn{2}{|c|}{ Values } & & & \\
\hline Variables & Unit & Significant & lower & higher & -1 & $\mathbf{0}$ & 1 \\
\hline Smelting Time & Minutes & $\mathrm{A}$ & 30 & 60 & 30 & 45 & 60 \\
\hline Smelting Temperature & Degree & $\mathrm{B}$ & 1450 & 1550 & 1450 & 1500 & 1550 \\
\hline Lime Percentage & $\%$ & $\mathrm{C}$ & 4 & 12 & 4 & 8 & 12 \\
\hline
\end{tabular}

The analysis of results of ANOVA for response surface quadratic models for Pure Metal Recovery with interrupted Slag in weight percentage of smelted samples are presented in Table 4, which shows that the Model F-value of 163.12 implies the model is significant. 
Table 4: Shows results of the model

\begin{tabular}{|l|l|}
\hline \multicolumn{2}{|l|}{ Statistical results of the ANOVA } \\
\hline Statistical results & \\
\hline Model F-value & 163.12 \\
\hline Model Prob>F & $<0.05$ \\
\hline C.V. \% & 0.36 \\
\hline R-Squared & 0.9953 \\
\hline Adj R-Squared & 0.9892 \\
\hline Pred R-Squared & 0.9522 \\
\hline Adeq Precision & 43.405 \\
\hline
\end{tabular}

There is only a $0.01 \%$ chance that a "Model F-Value" large could occur due to noise. Values of "Prob > F" less than 0.0500 indicate model terms are significant. In this case A, $\mathrm{B}, \mathrm{C}, \mathrm{AC}, \mathrm{BC}, \mathrm{A}^{2}, \mathrm{~B}^{2}, \mathrm{C}^{2}$ are significant model terms. Values greater than 0.1000 indicate the model terms are not significant. As per the table value R-Squared of 0.9953 is in reasonable agreement with the Adj R-Squared of 0.9892 that is the difference is less than 0.2. Adeq Precision measures the signal to noise ratio. A ratio greater than 4 is desirable. Our study exhibits ratio of 43.405 indicating adequate signal. This model can be used to navigate the design space. The coefficient of variance $(\mathrm{CV})$ for slag metal recovery in weight percentage is calculated to be $0.36 \%$. Considering the values of all the parameter of ANOVA statistical result of the model is found to be significant in this work. The model perform 17 batch runs as shown in Table 5 by using the design expert 9 software and it follow one second order quadratic equation (equation no-1) to calculated the Pure Metal Recovery with interrupted Slag in weight percentage of the smelted samples.

Table 5: 17 set of experimental variables of the box behnken design (BBD)

\begin{tabular}{|l|l|l|l|l|}
\hline \multirow{2}{*}{$\begin{array}{l}\text { Experimental } \\
\text { Set number }\end{array}$} & A & Parameters & C & $\begin{array}{l}\text { Pure Metal Recovery with } \\
\text { interrupted Slag }\end{array}$ \\
\cline { 2 - 5 } & & B & & 80.25 \\
\hline 1 & 45.00 & 1450.00 & 4.00 & 75.25 \\
\hline 2 & 45.00 & 1500.00 & 8.00 & 77.18 \\
\hline 3 & 30.00 & 1500.00 & 12.00 & 75.47 \\
\hline 4 & 45.00 & 1500.00 & 8.00 & 78.89 \\
\hline 5 & 60.00 & 1500.00 & 4.00 & 76.23 \\
\hline 6 & 45.00 & 1450.00 & 12.00 & 71.42 \\
\hline 7 & 45.00 & 1550.00 & 12.00 & 79.23 \\
\hline 8 & 30.00 & 1500.00 & 4.00 & 73.19 \\
\hline 9 & 60.00 & 1550.00 & 8.00 & 76.41 \\
\hline 10 & 60.00 & 1450.00 & 8.00 & 78.96 \\
\hline 11 & 30.00 & 1450.00 & 8.00 & 78.19 \\
\hline 12 & 45.00 & 1550.00 & 4.00 & 74.83 \\
\hline 13 & 45.00 & 1500.00 & 8.00 & 76.24 \\
\hline 14 & 30.00 & 1550.00 & 8.00 & 70.89 \\
\hline 15 & 60.00 & 1500.00 & 12.00 & 75.22 \\
\hline 16 & 45.00 & 1500.00 & 8.00 & 75.13 \\
\hline 17 & 45.00 & 1500.00 & 8.00 & \\
\hline
\end{tabular}

\section{Final Equation in Terms of Coded Factors:}

Pure Metal with slag Surface $=+75.02-1.53 * \mathrm{~A}-1.60 * \mathrm{~B}$

$$
+0.60 * \mathrm{~A}^{2}+0.58 * \mathrm{~B}^{2}+
$$

$0.93 * \mathrm{C}^{2}$ .equation no 1

\section{Final Equation in Terms of Actual Factors:}

Pure Metal with slag Surface $=+611.55125-0.14458 *$ Time $-0.69753 *$ Temperature $+4.69563 *$ Lime- $0.024792 *$

Time* Lime $-3.43750 \mathrm{E}-003 *$ Temperature * Lime $+2.67778 \mathrm{E}-003 *$ Time $^{2}+2.31000 \mathrm{E}-004 *$ Temperature $^{2}+$ $0.057812 *$ Lime $^{2}$ .equation no 2
The equation shows to determine P-value of the significance of individual coefficient is calculated. Higher significance of

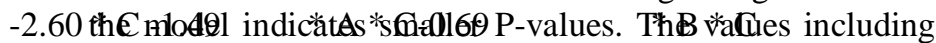
the independent variables $\mathrm{A}, \mathrm{B}, \mathrm{C}$ and the interacting variables $\mathrm{AB}, \mathrm{AC}, \mathrm{BC}$ as well as quadratic variables $\mathrm{A}^{2}, \mathrm{~B}^{2}$, $C^{2}$ are significant variables.

The Model predicted value and actual value of Pure Metal Recovery with interrupted Slag surface in weight percentage of the smelted samples are given Fig. 4. The figure shows that the model actual and predicted value closed each other. That result implies the model is significant. 


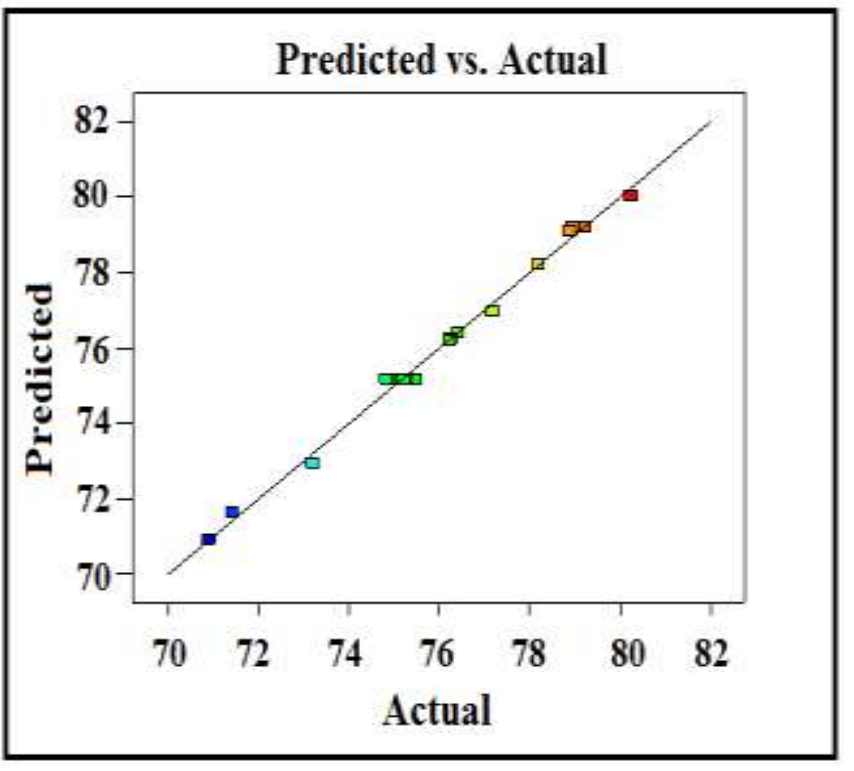

Fig. 4: Model predicted and actual value

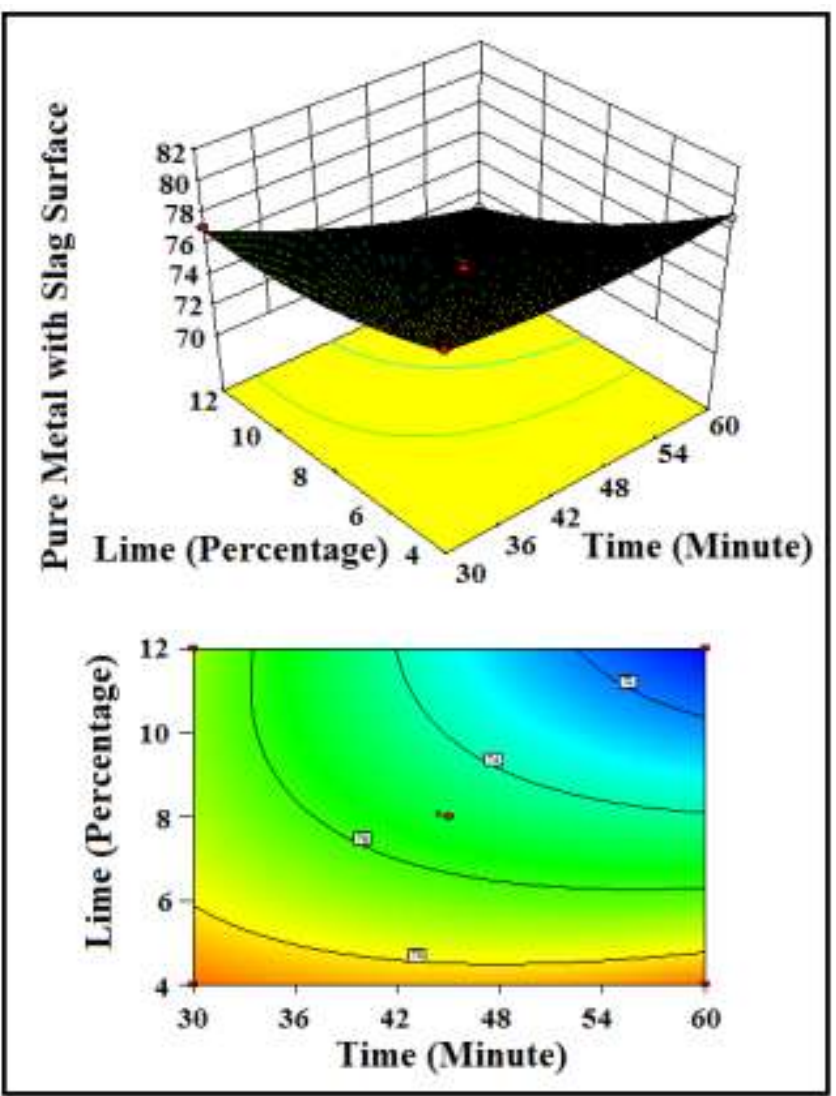

Fig. 5: Pure metal with slag surface second-order 3D response surface along with the contour plot as a function of percentage of lime and smelting time

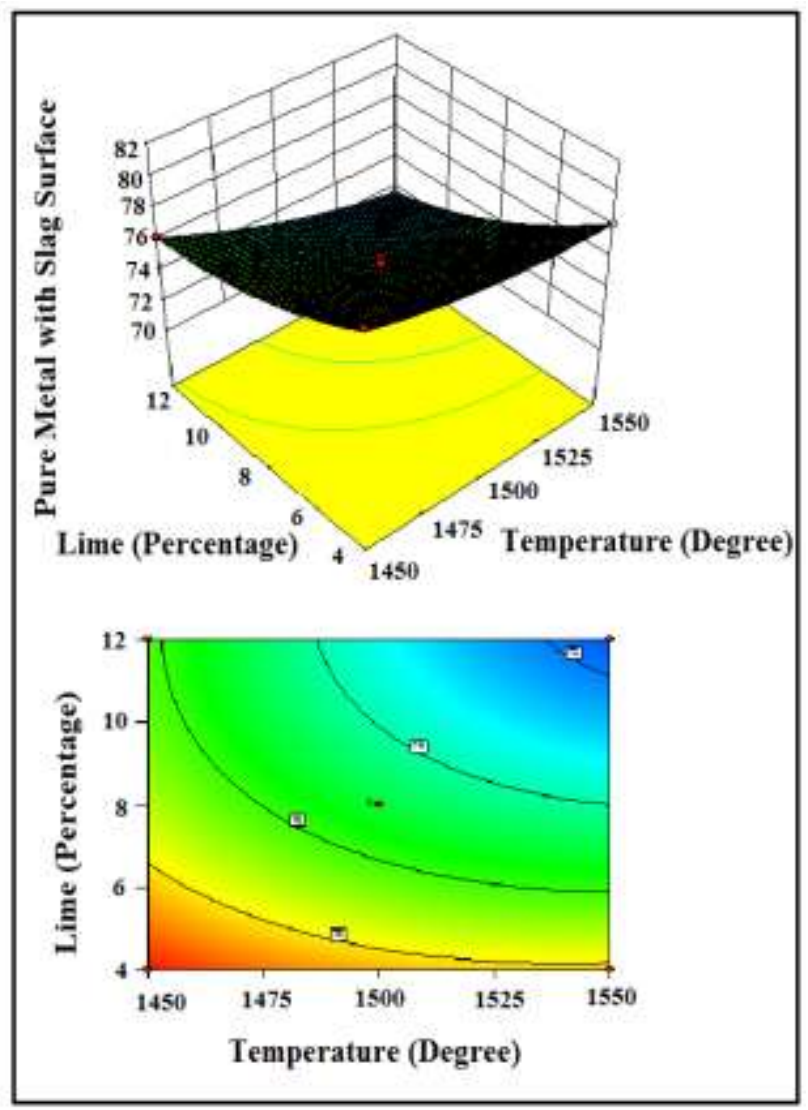

Fig. 6: Pure metal with slag surface second-order 3D response surface along with the contour plot as a function of percentage of lime and smelting temperature

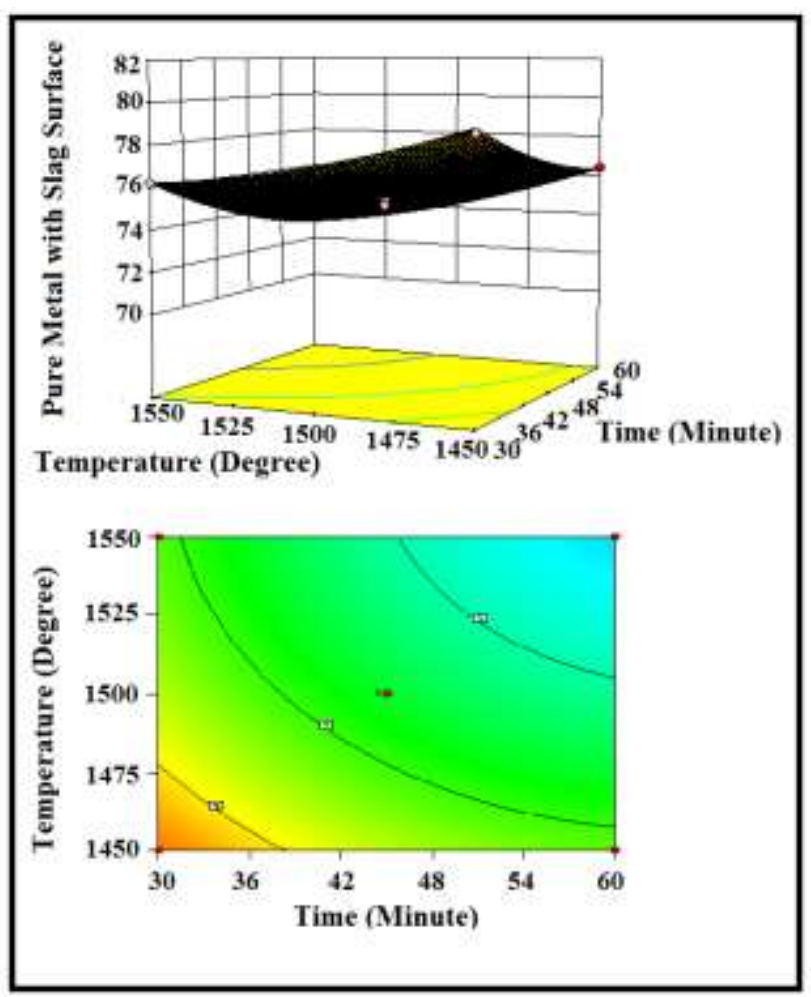

Fig. 7: Pure metal with slag surface second-order 3D response surface along with the contour plot as a function of smelting temperature and time 
Fig. 5 shows the second-order 3D response surface plot along with contour plot of pure metal with slag surface as a function of smelting time and lime percentage, while Fig. 6 shows pure metal with slag surface along with the contour plot as a function of smelting temperature and lime percentage,. Further in Fig.7 pure metal with slag surface as is shown along with the contour plot as a function of smelting temperature and time. From the analysis of Figs. 5, 6 and 7, the optimisation results of the model for pure metal with slag surface of the reduced samples are determined. The optimised values of smelting time and temperature are found to be 45 minute and $1500^{\circ} \mathrm{C}$ respectively along with 8 $\%$ of lime.

The RS plot in Fig. 5 shows that pure metal with slag surface increases with time and maximum achieved at $8 \%$ of lime. Fig. 6 shows that pure metal with slag surface decreases with temperature but maximum smelting is achieved at $8 \%$ of lime. Fig. 7 indicates that pure metal with slag surface decreases with increase in time and temperature. It can be inferred that time and \% of lime has more influence on the pure metal with slag surface than temperature.

\subsection{Compare the Experimental and Model Value}

\section{Analysis}

According to the model the 17 set of experiments are conducted from which the experimental and model values are recorded on the basis of Pure Metal Recovery with interrupted Slag which are given in the Table. 6. The deviation of the experimental results from values given by the model is found to be less than $1 \%$. Hence it can be concluded from the result that the experimental values properly match the model. Graphical analysis of experimental and model value with set of reaction which is given in the Fig. 8.

Table 6: Compare the Experimental and Model Value Analysis

\begin{tabular}{|l|l|l|l|}
\hline Experimental set Number & Experimental Value & Model value & Error \\
\hline 1 & 80.25 & 80.22 & 0.037397 \\
\hline 2 & 75.25 & 75.2 & 0 \\
\hline 3 & 77.18 & 77.15 & 0.038885 \\
\hline 4 & 75.47 & 75.2 & 0.359043 \\
\hline 5 & 78.89 & 79.29 & -0.50448 \\
\hline 6 & 76.23 & 76.4 & -0.22251 \\
\hline 7 & 71.42 & 71.82 & -0.55695 \\
\hline 8 & 79.23 & 80.15 & -1.14785 \\
\hline 9 & 73.19 & 73.25 & -0.08191 \\
\hline 10 & 76.41 & 76.45 & -0.05232 \\
\hline 11 & 78.96 & 79.51 & -0.69174 \\
\hline 12 & 78.19 & 78.4 & -0.26786 \\
\hline 13 & 74.83 & 75.2 & -0.49202 \\
\hline 14 & 76.24 & 76.31 & -0.09173 \\
\hline 15 & 70.89 & 71.11 & -0.30938 \\
\hline 16 & 75.22 & 75.2 & 0.026596 \\
\hline 17 & 75.13 & 75.2 & -0.09309 \\
\hline
\end{tabular}

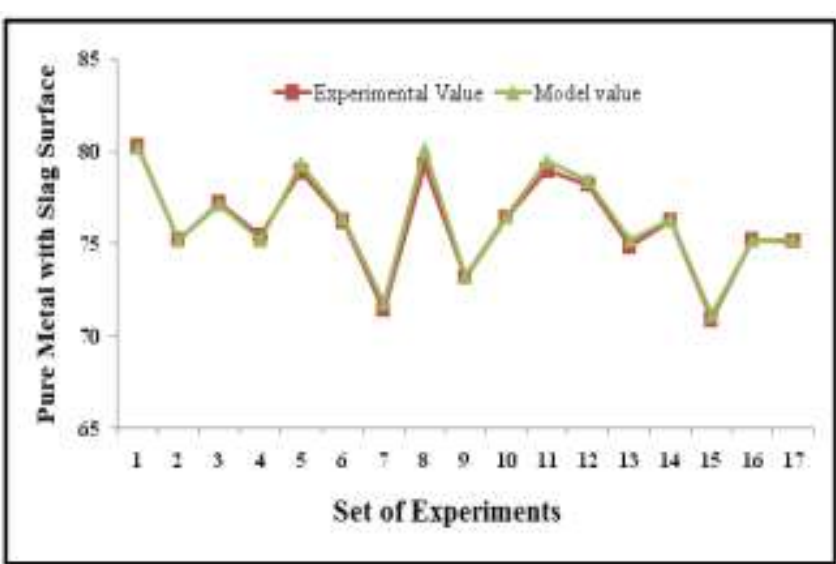

Fig. 8: Graphical analysis of experimental and model value with set of reaction
3.10 XRD Analysis of Smelted Samples (Metal Phase)

XRD pattern of the smelting sample at $1550^{\circ} \mathrm{C}$ in 60 minutes is given in Fig. 9. Only the peak of $\mathrm{Fe}$ is present in the XRD plots indicating complete formation of $\mathrm{Fe}$. 


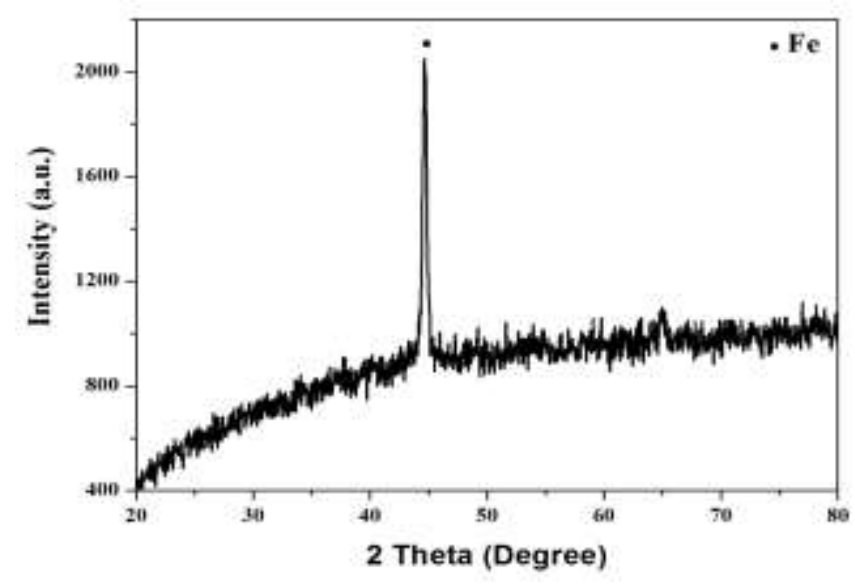

Fig. 9: XRD pattern of the metal surface of smelting sample heat treated at $1550^{\circ} \mathrm{C}$ for 60 minutes with $12 \%$ lime

\subsection{OES Analysis of Smelted Samples:}

Characterization of melted samples is done using Optical emission spectrometer (Shimadzu GVM-1014S made in China). OES analysis of the smelted samples, heat treated at $1550^{\circ} \mathrm{C}$ for 60 minutes with $12 \%$ lime, is given in Table. 7.

Table 7: OES results of the metal part of the smelted samples heat treated at $1550^{\circ} \mathrm{C}$ for 60 minutes with $12 \%$

\begin{tabular}{|c|c|c|c|c|c|c|}
\hline \multicolumn{7}{|c|}{ lime } \\
\hline $\mathrm{Fe}$ & $\mathrm{C}$ & $\mathrm{Si}$ & $\mathrm{Mn}$ & $\mathrm{S}$ & $\mathrm{P}$ & $\mathrm{Ti}$ \\
\hline 93.79 & 2.25 & 3.47 & 0.05 & 0.12 & 0.081 & 0.24 \\
\hline
\end{tabular}

It is observed from the OES analysis that the composition of the metallic phase comes out to be almost similar to that of pig iron, with the iron content slightly lower than the latter. Also, Silicon content is found to be higher, due to the direct use of boiler grade coal and lesser degree of metallization than pig iron produced from blast furnace.

\subsection{SEM and EDX Analysis of Smelted Samples}

\section{(Metal Phase):}

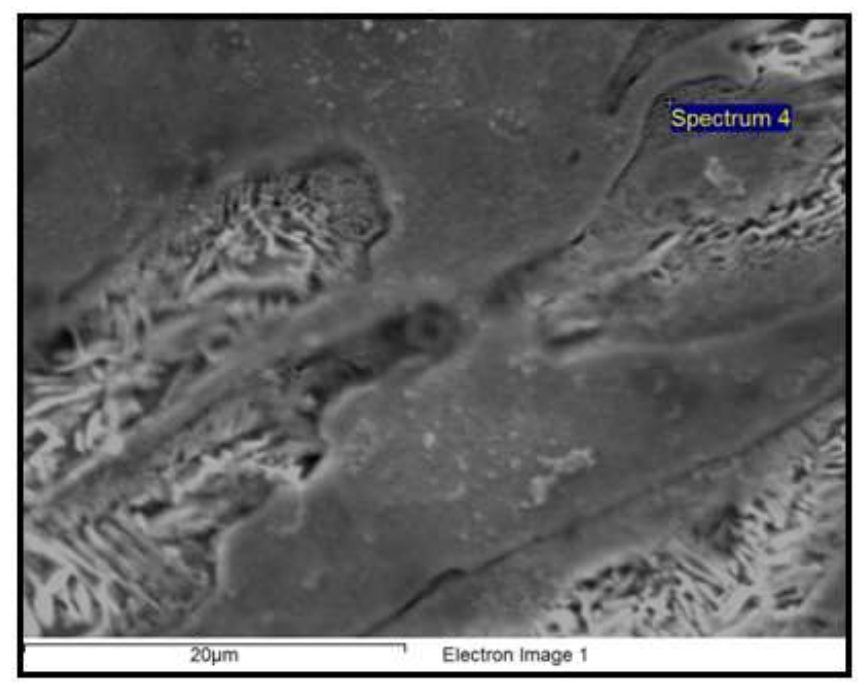

Fig. 10: SEM micro photograph of the smelt nuggets samples of metal surface heated at $1550^{\circ} \mathrm{C}$ for 60 minutes with $12 \%$ lime
SEM micro photograph of the smelt nuggets samples of metal surface heated at $1550^{\circ} \mathrm{C}$ for 60 minutes is given Fig. 10 in closed atmosphere. The image shows the metallic surface of the smelted samples.

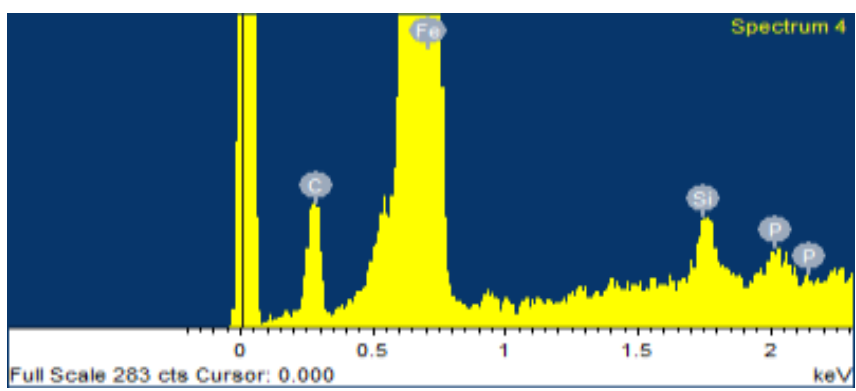

Fig. 11: Fig. 15: EDX plot of the metal phase heated at $1550^{\circ} \mathrm{C}$ for 60 minutes with $12 \%$ lime

The corresponding EDX analysis is shown in Fig. 11 which indicates the presence of major elemental $\mathrm{Fe}$ and small amount of $\mathrm{C} \mathrm{Si}$ and $\mathrm{P}$ in the heat treated sample. Table 10 represents the weight percentage and atomic percentage of the elements in the sample after smelting.

Table 8: EDX Results of metal phase of the smelting sample with $12 \%$ lime

\begin{tabular}{|l|l|l|}
\hline Element & Weight\% & Atomic\% \\
\hline C K & 0.06 & 0.28 \\
\hline Si K & 0.97 & 1.91 \\
\hline P K & 0.49 & 0.86 \\
\hline Fe K & 98.48 & 96.95 \\
\hline Totals & $\mathbf{1 0 0 . 0 0}$ & $\mathbf{1 0 0 . 0 0}$ \\
\hline
\end{tabular}

\subsection{Microstructure Analysis of Smelted Samples}

\section{(Metal Phase)}

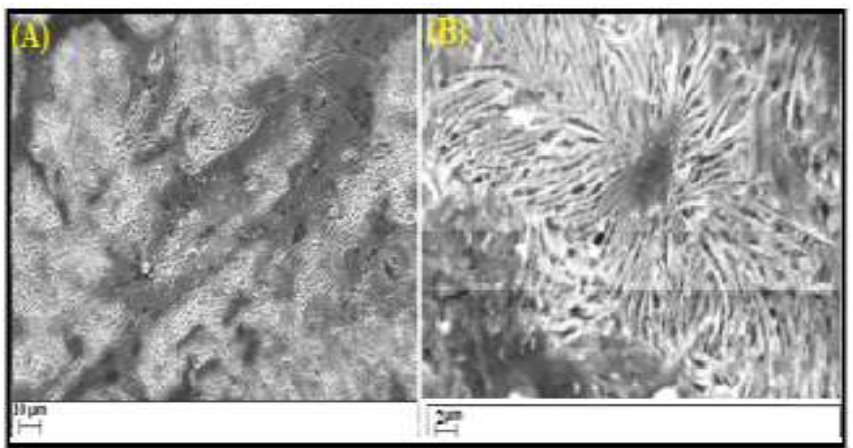

Fig. 12 (A)-(B): Microstructure of the samples smelted at $1550^{\circ} \mathrm{C}$ for 60 minute with $12 \%$ lime in different magnification (A) $10 \mu \mathrm{m}$ (B) $2 \mu \mathrm{m}$

Microstructure analysis of samples of the smelt nuggets heated at $1550 \mathrm{c}$ for 60 minutes and air cooled is given Fig. 12. Both the image shows the dendrite microstructure of the smelted samples. In Fig.12 (A) with lower magnification, the dendrites are not resolved whereas, in the Fig. 12(B), with higher magnification the dendrites are clearly resolved. Both the images Fig.12 (A) and 12(B) shows ferrite phase with dispersed carbon. 


\subsection{XRD Analysis of Smelted Samples (Slag Phase)}

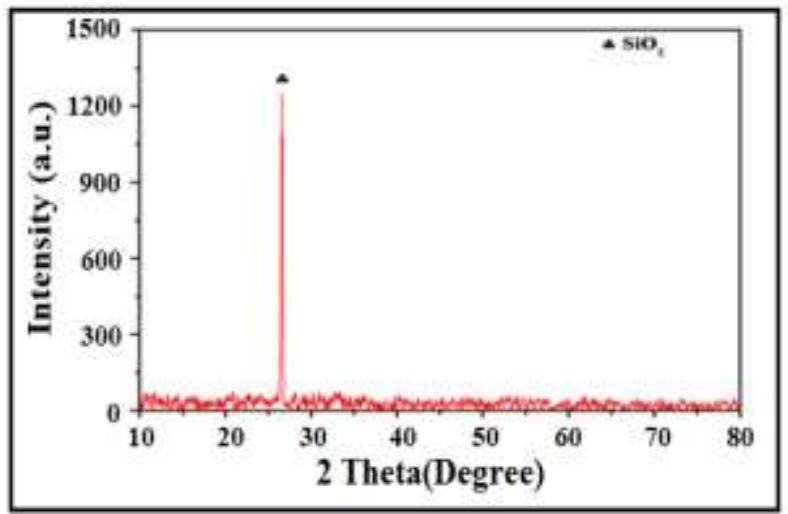

Fig. 13: $\mathrm{XRD}$ analysis of the Slag phase heated at $1550^{\circ} \mathrm{C}$ for 60 minutes with $12 \%$ lime

$\mathrm{XRD}$ analysis of the slag phase of the smelting sample is given in Fig 13. It is observed that the major peak is of silicon oxide $\left(\mathrm{SiO}_{2}\right)$.

\subsection{SEM and EDX Analysis of Smelted Samples}

\section{(Slag Phase)}

SEM micro photograph of the melt nuggets samples of slag surface are heated at $1550^{\circ} \mathrm{C}$ for 60 minutes is given Fig. 14 in closed atmosphere. The image shows non-uniform sizedistribution of the silicon oxides particles.

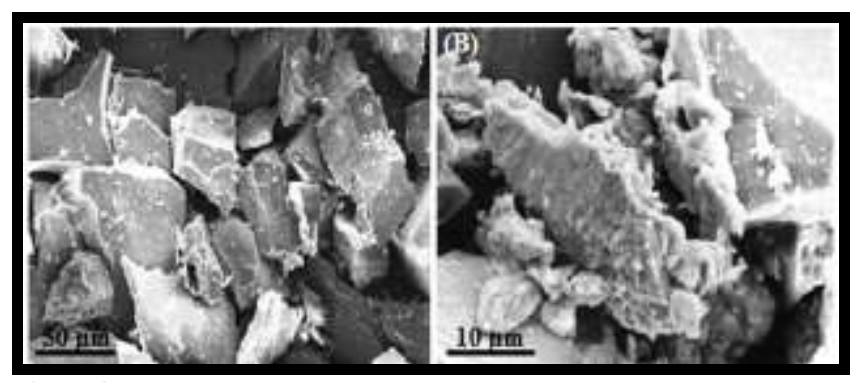

Fig. 14: SEM micro photograph of the melt nuggets samples of slag surface heated at $1550^{\circ} \mathrm{C}$ for 60 minutes with $12 \%$ lime

The corresponding EDX analysis is shown in Fig. 15 which indicates the presence of elemental $\mathrm{Fe}, \mathrm{Si}, \mathrm{O}, \mathrm{Ca}$ and $\mathrm{Al}$ in the heat treated sample. Table 9 represents the weight percentage and atomic percentage of the elements in the sample after smelting.

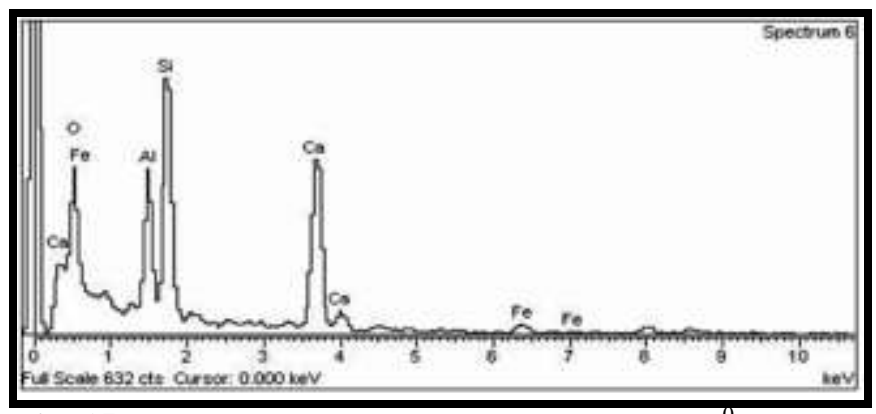

Fig. 15: EDX plot of the slag phase heated at $1550^{\circ} \mathrm{C}$ for 60 minutes with $12 \%$ lime
Table 9: EDX Results of slag phase of the smelting sample with $12 \%$ lime

\section{CONCLUSION:}

\begin{tabular}{|l|l|l|}
\hline Element & Weight\% & Atomic\% \\
\hline O K & 46.18 & 63.33 \\
\hline Al K & 10.63 & 8.64 \\
\hline Si K & 22.51 & 17.03 \\
\hline Ca K & 18.00 & 9.95 \\
\hline Fe K & 2.69 & 1.06 \\
\hline Totals & $\mathbf{1 0 0 . 0 0}$ & $\mathbf{1 0 0 . 0 0}$ \\
\hline
\end{tabular}

* Iron ore fines with coke dust and boiler grade coal can be successfully used for reduction of iron carbon composites in the form of nuggets. This reduced nugget is directly charged in raising hearth furnace for pig iron production.

* The numbers of smelting experiments are reduced using the BBD model. The optimized values of the parameters obtained from this model for maximum pure metal with slag surface are in complete agreement with the experimental results.

* Smelting of the reduced samples is carried out successfully at three different temperatures, times and lime percentage. Good separation of slag and metal phase with higher temperature, time and lime percentage are achieved.

* XRD analysis confirms the presence of pure iron. OES analysis gives $93.79 \%$ metallic $\mathrm{Fe}$ is present in the metallic part of the smelted nugget. OES analysis shows partially similar composition of smelted sample to that of pig iron.

* XRD study of the slag confirms the presence of silica, and EDX analysis shows other oxides phase in the slag.

\section{ACKNOWLEDGEMENTS}

The authors would like to thank Mr. Bitan Kumar Sarkar, Amit Kumar Bhandary, Arnab De and Maharshi Ghosh Dastidar, Research Scholar, Metallurgical \& Material Engineering, Jadavpur University, Kolkata.

\section{REFERENCES}

[1] World Steel Association. www.worldsteel.org

[2] World Coal Association. www.worldcoal.org

[3] Indian Bureau of Mines, Mineral Information.www.ibm.nic.in

[4] P. Bukovec, V. Kroselj, S. Turk, F. Vrecer, "Optimization of melt pelletization in a high shear mixer" International Journal of Pharmaceutics, 381 (2009) pp 192-198

[5] Kulchaya Tanong, Lucie Coudert, Guy Mercier, JeanFrancois Blais," Recovery of metals from a mixture of various spent batteries by a hydrometallurgical process" Journal of Environmental Management 181 (2016) pp 95-107

[6] M. Eisapour , A. Keshtkar , M.A. Moosavian , A. Rashidi " Bioleaching of uranium in batch stirred tank reactor: Process optimization using Box-Behnken design" Journal of Annals of Nuclear Energy 54 (2013) pp 245-250 
[7] Mehmet Kul, Kursad Oguz Oskay, Mehmet Simsir, Halit Subutay, Habip Kirgezen, "Optimization of selective leaching of $\mathrm{Zn}$ from electric arc furnace steelmaking dust using response surface methodology" Trans. Nonferrous Met. Soc. China 25(2015) pp 2753-2762

[8] N. Aslan , R. Fidan, "Optimization of $\mathrm{Pb}$ flotation using statistical technique and quadratic programming" Separation and Purification Technology 62 (2008) 160165

[9] Ding Yin-gui, Wang Jing-song, Wang Guang, Ma Sai, Xue Qing-guo "Comprehensive Utilization of Paigeite Ore Using Iron Nugget Making Process" Journal of Iron and Steel Research, International. 2012, 19(6): 0913

[10] Alberto Eloy Anduze Nogueira; Marcelo Breda Mourão; Cyro Takano;Dener Martins dos Santos, "Effect of slag composition on iron nuggets formation from carbon composite pellets" Mat. Res. vol.13 no.2 São Carlos Apr./June 2010.

[11] Takashi Matsui, Natsuo Ishiwata, Yoshiaki Hara and Kanji Takeda "Influence of Gangue Composition on Melting Behavior of Coal-Reduced Iron Mixture" Ironmakinig \& Environmental Process Research Dept.,Steel Research Lab., JFE Steel Corporation, 1 Kawasaki-cho, Chuo-ku,Chiba 260-0835 Japan.

[12] Mohammad Sheikhshab Bafghi, Hirohide Kurimoto, Masamichi Sano "Effect of Slag Foaming on the Reduction of lron Oxide in molten slag by Graphite" ISIJ International, Vol. 32 (1 992), No. 10, pp. 1084-1 090 .

[13] Guo Zhancheng, Xie Yusheng , Wang Daguang "Evaluation of sulfur distribution in the process of coal-based smelting reduction iron making" Institute of Chemical Metallurgy, Energy Convers. Mgmt Vol. 38, No. 10-13, pp. 1413- 1419, 1997.

[14] M. Benvenuti, A. Orlando , D. Borrini , L. Chiarantini , P. Costagliola , C. Mazzotta ,V. Rimondi "Experimental smelting of iron ores from Elba Island (Tuscany, Italy): Results and implications for the reconstruction of ancient metallurgical processes and iron provenance" Journal of Archaeological Science 70 (2016) 1-14

[15] Hiroyuki Katayamtae.Tetsuharu Ibaraki.Takamasaohno, Masao Yamauchhi, Hiroshi Hirata, Takeo Inomoto "The Characteristics and the Function of a Thick Slag Layer in the Smelting Reduction Process" ISIJ International, Vol. 33 (1993), No, 1, pp. 124132

[16] Basak Anameric and S. Komar Kawatra "The Microstructure of the Pig Iron Nuggets" ISIJ International, Vol. 47 (2007), No. 1, pp. 53-61

[17] Guang Wang, Jingsong Wang, Yingui Ding, Sai Ma nd Qingguo Xue "New Separation Method of Boron and Iron from Ludwigite Based on Carbon Bearing Pellet Reduction and Melting Technology" ISIJ International, Vol. 52 (2012), No. 1, pp. 45-51

[18] N. Narcin, S. Aydm, K. Segen, F. Dikec "Reduction of iron ore pellets with domestic lignite coal in a rotary tube furnace" Chemical and Metallurgical Eng. Dept., Istanbul Technical University, 80626, Maslak, Istanbul, Turkey Int. J. Miner. Process, 43 (1995) pp 49-59

\section{APPENDIX: 1}

A nugget contains $4 \%$ molasses $+4 \%$ bentonite $+2 \%$ moisture + mixture $(50 \%$ of boiler grade coal $+50 \%$ of coke dust) + rest iron ore

Experimental weight before reduction $=0.43 \mathrm{gm}$ molasses + $0.43 \mathrm{gm}$ bentonite $+0.08 \mathrm{gm}$ moisture $+3.11 \mathrm{gm}$ mixture of blending boiler grade coal and coke dust +7.75 gm iron ore

Total weight of the nuggets $=11.80 \mathrm{gm}$

100 gm ore contains 91.5 gm hematite

$7.75 \mathrm{gm} \mathrm{"} \quad 7.09 \mathrm{gm} "$

91.5 gm hematite contains 64 gm iron (From WDXRF and Chemical Analysis)
$7.09 \mathrm{gm}$
$4.95 \mathrm{gm}$ iron

Oxygen content $=(7.09-4.95) \mathrm{gm}=2.14 \mathrm{gm}$

Loss on heating $=95 \%$ of molasses $+18 \%$ of bentonite + oxygen contained in hematite $+100 \%$ of moisture + total weight of blending boiler grade coal and coke dust

Weight loss from the nugget in case of $100 \%$ reduction $=$ $(0.41+0.08+2.14+0.08+2) \mathrm{gm}=4.71 \mathrm{gm}$

Remaining weight after reduction (for $100 \%)=(11.80$ 4.71) $\mathrm{gm}=7.09 \mathrm{gm}$

Experimental weight after reduction $=7.57 \mathrm{gm}$

Experimental weight loss of the nuggets after reduction $=$ $(11.80-7.57) \mathrm{gm}=4.23 \mathrm{gm}$

Percentage of weight loss $=($ Experimental weight loss $/$ Weight loss for $100 \%$ reduction) $* 100$

\section{Hence, percentage of weight loss $=(4.23 \mathrm{gm} / 4.71 \mathrm{gm}) *$ $100=89.80 \%$}

In case of reduction for each nugget, some weight loss is fixed due to loss of molasses, bentonite, moisture and VM \& moisture content of blended boiler grade coal and coke dust (Except fixed carbon).

Fixed weight loss of the nuggets after reduction $=(0.41+$ $0.08+0.08+0.41) \mathrm{gm}=0.98 \mathrm{gm}$

Hence, total weight loss after reduction $=(4.23-0.98) \mathrm{gm}=$ $3.25 \mathrm{gm}$

Extent of reduction

$=$ (weight of iron oxide + fixed carbon of boiler grade coal and coke dust after reduction) / (weight of iron oxide + fixed carbon of boiler grade coal and coke dust after $100 \%$ reduction)

\section{Percentage of extent of reduction}

$=[3.25 \mathrm{gm} / 2.14+(2-0.41) \mathrm{gm}] * 100=87.13 \%$ 